\title{
A Simple and Safe Technique of Creating Closed Pneumoperitoneum
}

\author{
Amarendra Nath Roy $\cdot$ Supriyo Ghatak
}

Received: 12 November 2010 / Accepted: 4 June 2012 /Published online: 20 June 2012

(C) Association of Surgeons of India 2012

\begin{abstract}
Laparoscopic surgery has become the standard of care for many diseases like symptomatic gallstone disease, acute appendicitis, achalasia and gastroesophageal reflux disease. One of the key steps in the procedure is to obtain pneumoperitoneum and insert the first trocar safely. We describe a simple technique which detects the precise entry point when the reusable metallic Veress needle enters the peritoneal cavity.
\end{abstract}

Keywords Abdominal · Bariatric · Bowel · Cholecystectomy · Complications $\cdot$ Pneumoperitoneum

Laparoscopic surgery has become the standard of care for many diseases such as symptomatic gallstone disease, acute appendicitis, achalasia and gastroesophageal reflux disease. One of the key steps in the procedure is to obtain pneumoperitoneum and insert the first trocar safely. Closed pneumoperitoneum is usually obtained by inserting a Veress needle through the abdominal wall inside the peritoneal cavity.

There are various tests described in the literature to confirm the position of the needle tip inside the peritoneal cavity. Atmospheric air is sucked into the abdomen with an audible hiss (Hiss test), aspiration of air into a partially filled syringe, free instillation of saline through the needle, sucking in of a drop of saline placed onto the hub of the Veress needle due to negative intraperitoneal pressure (Drop test), etc.-all these tests confirm the needle tip position once it is inside the

\section{A. N. Roy $\cdot$ S. Ghatak $(\bowtie)$}

Division of Surgical Gastroenterology, School of Digestive \&

Liver Diseases, Institute of Postgraduate Medical Education \&

Research, SSKM Hospitals,

244, Acharya, Jagadish Chandra Bose Road,

Kolkata 700020, India

e-mail: drsupriyo@yahoo.co.in

$$
\begin{aligned}
& \text { A. N. Roy } \\
& \text { e-mail: amar_royin@yahoo.com }
\end{aligned}
$$

peritoneal cavity [1]. We describe a simple technique which detects the precise entry point when the reusable metallic Veress needle enters the peritoneal cavity. This technique prevents overshooting of the needle inside the abdomen, thereby lessening the chance of any visceral injury.

A 5 cc syringe (without the plunger) with about $3 \mathrm{ml}$ saline in it is fitted with the reusable Veress needle. Keeping the air channel locked the needle is inserted as usual through the skin nick. When the needle is in the muscle layer, the lock is released. After that the needle is pushed further. As soon as the needle punctures the peritoneum the water of the syringe starts flowing through the needle. The flow of water confirms the intraperitoneal position of the needle tip. By this technique one can make pneumoperitoneum with the most superficial position of the needle tip inside the abdomen. We have used this technique in 25 consecutive patients of laparoscopic procedures without any difficulty in creating pneumoperitoneum.



\section{Reference}

1. Palanivelu C (2007) Laparoscopic space access. In: Palanivelu C (ed) Art of laparoscopic surgery, textbook and atlas, volume 1, 1st edn. Jaypee Brothers, pp. 59-68 